\title{
CD4 T Cell to CD8 T Cell Ratio Measurement
}

National Cancer Institute

\section{Source}

National Cancer Institute. CD4 T Cell to CD8 T Cell Ratio Measurement. NCI Thesaurus. Code C74637.

The determination of the ratio of CD4 T cells compared to CD8 T cells present in a sample. The measurement may be expressed as a ratio or percentage. 